14,13

\title{
Атомный состав и морфология тонких пленок ресвератрола на поверхности окисленного кремния и поликристаллического золота
}

\author{
() А.С. Комолов ${ }^{1}$, Э.Ф. Лазнева ${ }^{1}$, Н.Б. Герасимова ${ }^{1}$, В.С. Соболев ${ }^{1}$, Ю.А. Панина ${ }^{1}$, \\ С.А. Пшеничнюк ${ }^{2}$, Н.Л. Асфрандиаров ${ }^{2}$ \\ ${ }^{1}$ Санкт-Петербургский государственный университет, \\ Санкт-Петербург, Россия \\ ${ }^{2}$ Институт фризики молекул и кристаллов УФИЦ РАН, \\ Уфра, Россия \\ E-mail: a.komolov@spbu.ru
}

(Поступила в Редакцию 14 июня 2018 г.

В окончательной редакции 17 октября 2018 г.)

\begin{abstract}
Приведены результаты исследования атомного состава термически напыленных пленок полифенольного антиоксиданта - ресвератрола (RVL) - толщиной до $50 \mathrm{~nm}$, на поверхности окисленного кремния методом рентгеновской фотоэлектронной спектроскопии (XPS). Обнаружено, что площадь пор в пленке RVL составляет около $15 \%$ общей площади поверхности. Приведены результаты по изучению стабильности пленок RVL при обработке поверхности ионами $\mathrm{Ar}^{+}$с энергией $3 \mathrm{keV}$ при значениях электрического тока через образец порядка $1 \mu \mathrm{A}$ в течение $30 \mathrm{~s}$. Обработка привела к увеличению площади пор до $30-40 \%$, а отношение концентраций атомов C к O в пленке RVL как до ионной обработки поверхности, так и после не соответствовало химической формуле RVL-молекул. Методом атомносиловой микроскопии (AFM) в контактной моде с размером области сканирования порядка $10 \mu \mathrm{m} \times 10 \mu \mathrm{m}$ исследованы RVL-покрытия поверхности окисленного кремния и поликристаллического Au. Обнаружено, что пленки RVL создают зернистое и пористое покрытие поверхности подложек. Характерный размер зерен составлял $150-300 \mathrm{~nm}$ в плоскости поверхности образца, а характерный перепад высот достигал $30 \mathrm{~nm}$.
\end{abstract}

Работа выполнена при поддержке РФФИ (18-03-00020, 18-03-00179). В работе использовали оборудование научного парка СПбГУ „Физические методы исследования поверхности“, „Диагностика функциональных материалов для медицины, фармакологии и наноэлектроники“ и „Нанофотоника“.

DOI: 10.21883/FTT.2019.03.47257.161

\section{1. Введение}

Натуральные полифенольные соединения, такие как пицеатаннол, кверцетин и ресвератрол, широко известны вследствие своих и антиоксидантных свойств [1,2]. Один из механизмов воздействия антиоксидантов, приводящий к снижению концентрации свободных радикалов, обусловлен захватом молекулой антиоксиданта электрона, конкурирующим с захватом электрона молекулой кислорода [3-7]. Важную роль в реализации этого механизма играет энергетическое положение вакантных электронных орбиталей, то есть резонансных значений энергий отрицательных ионов полифенольных соединений в энергетическом диапазоне $0-5 \mathrm{eV}$ выше уровня вакуума $[6,7]$. Интерес исследователей привлекает молекулярная адсорбция полифенолов и формирование тонкопленочных структур на поверхности твердого тела [8]. Опубликованы результаты по формированию полифенольных молекулярных покрытий на поверхности оксида графена, углеродных нанотрубок, наночастиц золота и диоксида титана и кремния [9-12]. Поверхностные структуры на основе полифенольных молекул перспективны в плане применения в нанолитографии [13] и в связи с возможностями их использования в устройствах органической электроники, например, органических фотовольтаических ячейках $[14,15]$. Ранее мы исследовали резонансные энергии отрицательных ионов ресвератрола (рис. 1) методом спектроскопии диссоциативного захвата электронов [6], и для ультратонких пленок ряда малых сопряженных органических молекул было показано хорошее соответствие энергетического спектра молекулярных резонансов и спектра вакантных электронных орбиталей [16-19]. При исследованиях адсорбционного покрытия ресвератрола на поверхности углеродных нанотрубок были обнаружены изменения спектров оптического поглощения, изменения энергетического положения границ валентной зоны и зоны проводимости [10].

Следует отметить, что преобладающее количество опубликованных работ посвящено изучению свойств полифенольных молекул в газовой фазе или в растворе. Видимо, поэтому, несмотря на опубликованные исследования электронных и оптических свойств поверхностных структур на основе полифенольных молекул, авторам не удалось обнаружить систематических исследований по термическому осаждению пленок, контролю их стабильности для данного вида молекулярных материалов. 
Методы рентгеновской фотоэлектронной спектроскопии (XPS) и атомно-силовой микроскопии (AFM) позволяют непосредственно установить атомный состав и структуру, а также морфологию поверхности тонких органических пленок на поверхности твердого тела [20-24]. Вместе с этим XPS и другие электронноспектроскопические методы дают возможность оценить степень загрязнения органических пленок адсорбатами из атмосферы, что особенно важно при нанесении органических покрытий из раствора или при термическом вакуумном осаждении ex situ, а кроме того, исследовать стабильность органического материала при воздействии электронным или ионным пучком [24-26]. В настоящей работе приведены результаты исследования атомного состава термически напыленных тонких пленок ресвератрола на поверхности диоксида кремния методом рентгеновской фотоэлектронной спектроскопии (XPS). Приведены результаты по изучению стабильности пленок ресвератрола при воздействии ионным пучком и по изучению морфологии поверхности пленок ресвератрола на поверхности окисленного кремния и поликристаллического золота.

\section{2. Эксперимент}

Для нанесения пленок использовали реактив ресвератрол (RVL), коммерчески доступный в Sigma-Aldrich (рис. 1). Осаждение органического материала толщиной до $50 \mathrm{~nm}$ проводили путем термического осаждения в вакууме при базовом давлении $10^{-5}$ Ра при скорости осаждения около $1 \mathrm{~nm} / \mathrm{min}$. Температура нагрева реактива составляла около $200{ }^{\circ} \mathrm{C}$, что достаточно хорошо соответствует условиям сублимации RVL, применявшимся ранее при исследованиях методом спектроскопии диссоциативного захвата электронов [6]. Перед осаждением проводилось обезгаживание реактива в течение нескольких часов в вакуумной камере при температуpe $100^{\circ} \mathrm{C}$. В качестве подложек для нанесения пленок использовали пластины $\left(\mathrm{SiO}_{2}\right) \mathrm{n}-\mathrm{Si}$, предварительно очищенные в $10 \%$ растворе $\mathrm{HF}$ и смеси $\mathrm{H}_{2} \mathrm{O}_{2} / \mathrm{H}_{2} \mathrm{SO}_{4}$. После такой процедуры очистки на поверхности кремния формируется слой оксида кремния толщиной $3-5 \mathrm{~nm}$ с составом, близким к стехиометрическому [19,22,27,28]. Для формирования подложек поликристаллического золота слой золота толщиной до $100 \mathrm{~nm}$ наносили на поверхность пластины $\left(\mathrm{SiO}_{2}\right) \mathrm{n}-\mathrm{Si}$. Атомный состав по-<smiles>Oc1ccc(/C=C/c2cc(O)cc(O)c2)cc1</smiles>

Рис. 1. Структурная формула молекулы ресвератрола. верхностей подложек, использованных в работе, был подтвержден методом рентгеновской фотоэлектронной спектроскопии (XPS). Методом атомно-силовой микроскопии (AFM) оценили, что шероховатость поверхностей $\left(\mathrm{SiO}_{2}\right) \mathrm{n}-\mathrm{Si}$-подложек не превышала $1 \mathrm{~nm}$. Это является характерным для поверхностей монокристаллического кремния со слоем реального оксида и со слоем термически осажденного золота [22,27,29]. Для исследований методом XPS термически осажденные пленки RVL, толщиной около $50 \mathrm{~nm}$, помещали в комплексный фотоэлектронный спектрометр Escalab 250Xi (Thermo Fisher Scientific Inc.) с энергией фотонов $\mathrm{Al} K \alpha=1486 \mathrm{eV}$. Исследования проводили в условиях сверхвысокого вакуума порядка $10^{-7}$ Ра при комнатной температуре. Спектры остовных уровней были измерены при энергии пропускания анализатора $20 \mathrm{eV}$. Фокусировка падающего пучка фотонов определяла характерный размер исследуемой области поверхности около $650 \mu \mathrm{m}$. При анализе измеренных XPS-спектров использовали библиотеку стандартных XPS-спектров производителя оборудования, учитывали атомные факторы чувствительности регистрации сигнала [30]. Морфологию поверхности исследованных пленок RVL изучали с помощью методики AFM в контактной моде на микроскопе Integra Spectra instrument (Spectrum Instruments Ltd.).

\section{3. Результаты и обсуждение}

В XPS-спектре поверхности $\mathrm{Si} / \mathrm{SiO}_{2} / \mathrm{RVL}$, приготовленной ex situ, отчетливо наблюдались максимумы атомных компонент $\mathrm{C}_{1 s}, \mathrm{O}_{1 s}$ и $\mathrm{Si}_{2 p}$ (рис. 2 и 3, кривые 1). Максимум $\mathrm{C}_{1 s}$ расположен при значении энергии связи $284.5 \mathrm{eV}$ (рис. 2, кривая 1), что хорошо соответствует литературным данным по энергии связи атома углерода в графене или в составе ароматических органических молекул $[19,29,31]$. Присутствие атомов углерода, связанных с гидроксильной группой $(-\mathrm{OH})$, ожидаемое в случае исследованных молекул RVL, можно идентифицировать по компоненту $\mathrm{C}_{1 s}$ максимума в области энергий связи 285-286 eV [31,32]. Максимум $\mathrm{O}_{1 s}$ расположен при значении энергии связи $533 \mathrm{eV}$ (рис. 3, $a$, кривая 1). Такое энергетическое положение соответствует атомам кислорода, связанным одиночной связью с ароматическим атомом углерода [30-32], что согласуется со структурой RVL. C другой стороны, расположение $\mathrm{O}_{1 s}$ максимума при $533 \mathrm{eV}$ характерно и для атома кислорода в составе $\mathrm{SiO}_{2}[19,30]$. В случае исследованных образцов $\mathrm{Si} / \mathrm{SiO}_{2} / \mathrm{RVL}$ наличие измеренного XPS-сигнала, исходящего от подложки, было установлено по XPS-максимуму $\mathrm{Si}_{2 p}$ (рис. $3, b$, кривая 1). Вершина максимума $\mathrm{Si}_{2 p}$ при $99.5 \mathrm{eV}$ соответствует атомам кристаллического кремния, а вершина при $103.5 \mathrm{eV}$ характерна для атомов кремния в составе $\mathrm{SiO}_{2}[26,30]$. Так как толщина слоя $\mathrm{SiO}_{2}$ в использованных подложках составляла 3-5нм, то при условии наличия в пленках RVL пор анализируемая область захватывала и слой $\mathrm{SiO}_{2}$, и нижележащий слой кремния. 
С учетом относительных интенсивностей измеренных $\mathrm{C}_{1 s}, \mathrm{O}_{1 s}$ и $\mathrm{Si}_{2 p}$ XPS-максимумов и факторов чувствительности их регистрации [30] относительные концентрации атомных компонент $\mathrm{C}, \mathrm{O}$ и $\mathrm{Si}$ в исследованном образце $\mathrm{Si} / \mathrm{SiO}_{2} / \mathrm{RVL}$ составили приблизительно 60,25 , $15 \%$ соответственно. Таким образом, XPS-сигнал атомов $\mathrm{Si}$ исходит, по крайней мере, от $15 \%$ общей площади подложки, т.е. поверхность подложки, свободная от RVL-покрытия, составляет не менее $15 \%$ от полной площади поверхности. Из $25 \%$ относительной концентрации атомов кислорода примерно $10 \%$ следует связывать с атомами кислорода в составе слоя $\mathrm{SiO}_{2}$ с учетом того, что максимум $\mathrm{Si}_{2 p}$ при $99.5 \mathrm{eV}$ в 3 раза интенсивнее максимума $103.5 \mathrm{eV}$ (рис. $3, b$, кривая 1 ). Оставшаяся часть атомов кислорода, т.е. примерно $15 \%$ от суммарной относительной концентрации всех трех атомных компонент, находится в составе молекул RVL, либо в составе кислородсодержащих поверхностных адсорбатов. Отношение $60 \%$ к $15 \%$, т.е. $12: 3$, меньше отношения количества атомов $\mathrm{C}: \mathrm{O}$, согласно химической формуле молекул RVL $\left(\mathrm{C}_{14} \mathrm{H}_{12} \mathrm{O}_{3}\right)$, т.е. 14:3 (рис. 1). Достаточно хорошо известно, что поверхности, приготовленные ex situ, адсорбируют из воздуха кислородсодержащие и углеродсодержащие примеси $[22,29,33]$. Поэтому можно заключить, что с погрешностью $15-20 \%$ экспериментально измеренное соотношение количества атомов $\mathrm{C}: \mathrm{O}$ в пленке RVL хорошо соответствует химической формуле RVL-молекул (рис. 1).

C целью очистки образца от поверхностных адсорбатов и с целью оценки стабильности сформированных пленок RVL проводили процедуру бомбардировки поверхности образца ионами $\mathrm{Ar}^{+}$с энергией $3 \mathrm{keV}$. Ток через образец составлял при этом порядка $1 \mu \mathrm{A}$. После проведения одного цикла очистки, длительностью $30 \mathrm{~s}$, обнаружено значительное, в 3-4 раза, снижение интенсивности $\mathrm{O}_{1 s}$ XPS-максимума (рис. 3, $a$, кривая 2). Вместе с этим полностью исчез компонент максимума $\mathrm{Si}_{2 p}$ при $103.5 \mathrm{eV}$, исходящий от слоя $\mathrm{SiO}_{2}$, и примерно на $50 \%$ увеличилась интенсивность компонента максимума $\mathrm{Si}_{2 p}$ при $99.5 \mathrm{eV}$, исходящего от кристаллического кремния подложки (рис. $3, b$ ). Таким образом, в результате обработки ионным пучком слой $\mathrm{SiO}_{2}$ был удален из области пор пленки RVL. Следует считать, что и слой поверхностных адсорбатов был удален как из областей пор пленки RVL, так и с поверхности самой пленки RVL. Интенсивность $\mathrm{C}_{1 s}$ XPS-максимума в результате обработки ионным пучком практически не изменилась (рис. 2). Аналогично случаю поверхности исходного образца $\mathrm{Si} / \mathrm{SiO}_{2} / \mathrm{RVL}$, относительные концентрации основных атомных компонент были установлены и для $\mathrm{Ar}^{+}$обработанной поверхности. Значения относительных концентраций атомов $\mathrm{C}, \mathrm{O}$ и $\mathrm{Si}$ составили 55 , 10 и $35 \%$. Существенное увеличение относительной концентрации атомов $\mathrm{Si}$, по сравнению с поверхностью исходного образца $\mathrm{Si} / \mathrm{SiO}_{2} / \mathrm{RVL}$, говорит о том, что в результате ионной очистки значительно увеличилась пористость пленки RVL. Отношение 55 к 10\% концентраций атомов $\mathrm{C}$ к $\mathrm{O}$, как и в случае исходного

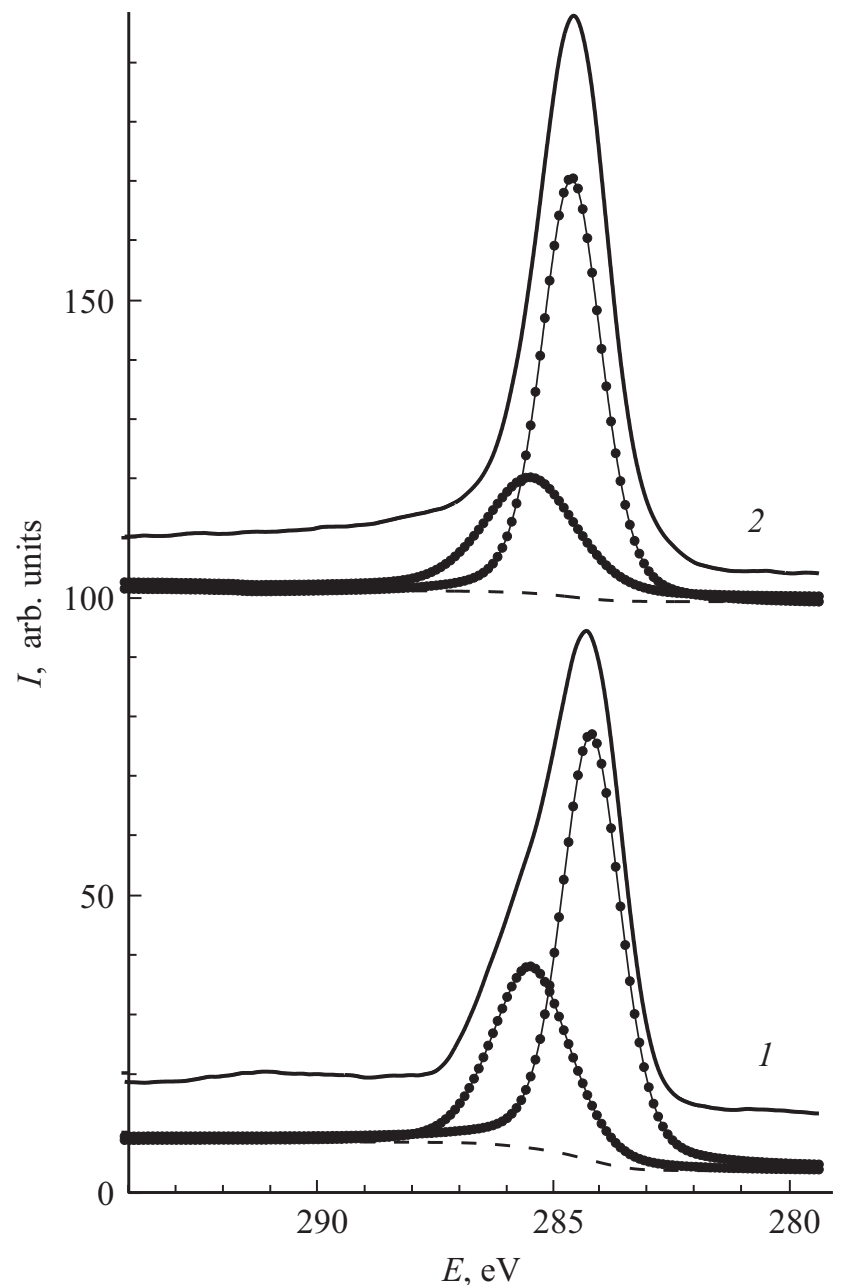

Рис. 2. Рентгеновский фотоэлектронный (XPS)-спектр поверхности $\mathrm{Si} / \mathrm{SiO}_{2} / \mathrm{RVL}$ в области максимума атомного компонента $C_{1 s}$. Кривая $1-$ без предварительной обработки, кривая 2 - после обработки ионами $\mathrm{Ar}^{+}$с энергией $3 \mathrm{keV}$ в течение $30 \mathrm{~s}$. Анализ компонент кривых 1 и 2 проводили путем фитинга функциями, содержащими $80 \%$ функции Гаусса и $20 \%$ функции Лоренца после вычитания фона вида функции Shirley. Два основных компонента каждой из кривых 1 и 2 (кривые -•-) и фоновые кривые (пунктир) сдвинуты в сторону меньших значений I примерно на 10 arb.units.

образца $\mathrm{Si} / \mathrm{SiO}_{2} / \mathrm{RVL}$, с учетом возможной погрешности $15-20 \%$ хорошо соответствует химической формуле RVL молекул (рис. 1).

Следует заметить, что в результате проведенной ионной очистки поверхности $\mathrm{Si} / \mathrm{SiO}_{2} / \mathrm{RVL}$ изменились положение и форма XPS-максимумов $\mathrm{C}_{1 s}$ и $\mathrm{O}_{1 s}$ (рис. 2 и $3, a)$. Примерно на $30 \%$ снизилась интенсивность компонента максимума $\mathrm{C}_{1 s}$ в области энергий связи $285-286 \mathrm{eV}$, который отчетливо наблюдался в виде уширения основного максимума до проведения ионной очистки (рис. 2, кривая 1). Это наиболее удобно наблюдать, сравнивая компоненты максимумов $\mathrm{C}_{1 s}$, полученные в результате вычитания фоновой функции и фитинга (рис. 2). Так как компонент в области энер- 

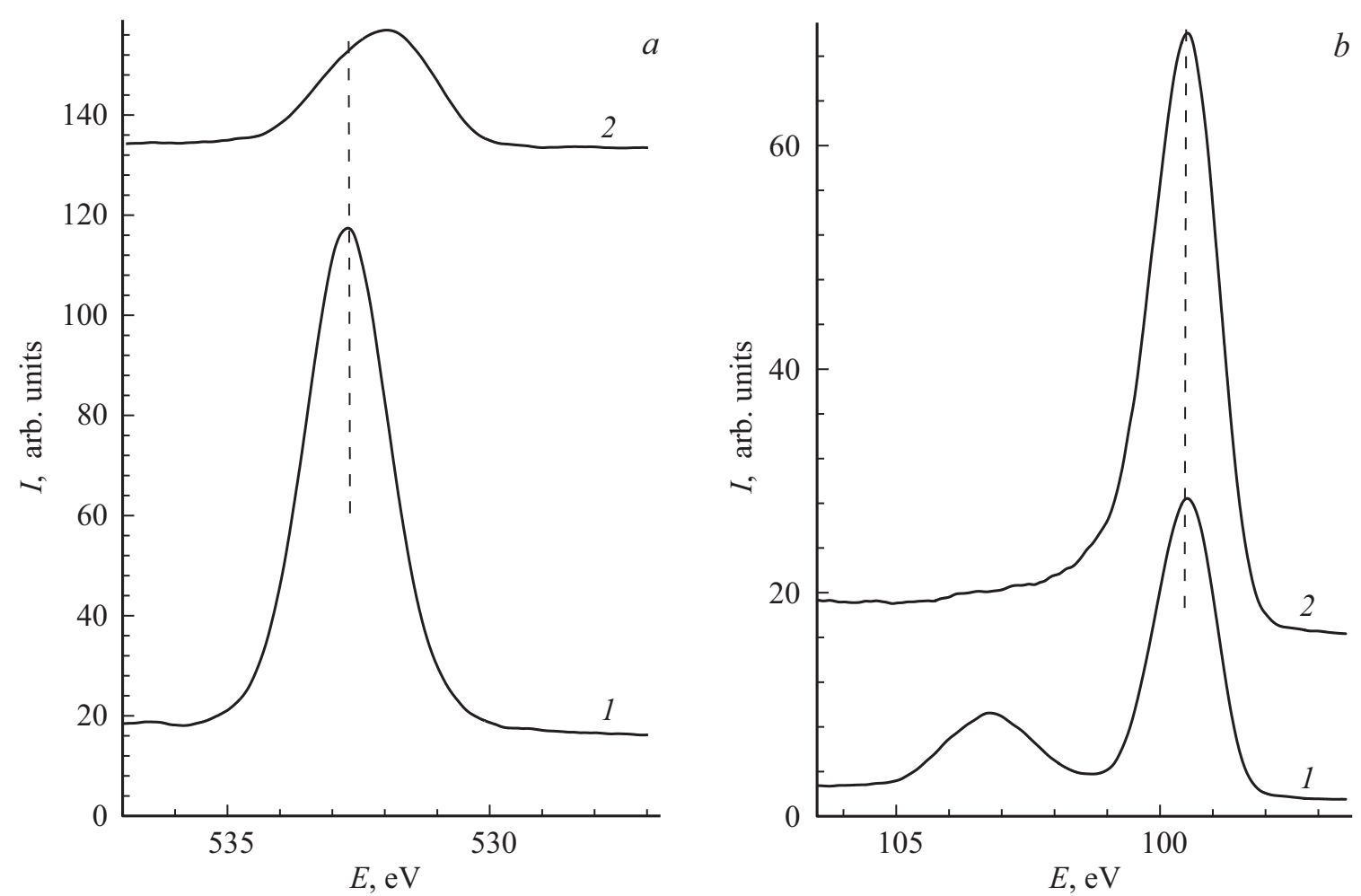

Рис. 3. Рентгеновский фотоэлектронный (XPS) спектр поверхности $\mathrm{Si} / \mathrm{SiO}_{2} / \mathrm{RVL}$ в области максимума атомного компонента $\mathrm{O}_{1 s}(a)$ и $\mathrm{Si}_{2 p}(b)$. Кривая 1 - без предварительной обработки, кривая 2 - после обработки ионами $\mathrm{Ar}^{+} \mathrm{c}$ энергией $3 \mathrm{keV}$ в течение $30 \mathrm{~s}$. Вертикальные пунктирные линии приведены для удобства сравнения положения максимумов.

гий связи 285-286 eV обусловлен атомами углерода, связанными с гидроксильной группой (-OH) [31-33], то можно предположить, что воздействие ионного пучка приводит к частичной десорбции -ОН-групп или к изменению энергетического состояния атомов углерода в XC-OH-связи в молекуле RVL (рис. 1). Вместе c этим энергетическое положение основной вершины максимума $\mathrm{C}_{1 s}$ сдвинулось до $0.5 \mathrm{eV}$ в сторону более высоких значений энергий связи. Такой сдвиг максимума $\mathrm{C} 1 \mathrm{~s}$ говорит об уменьшении степени ароматичности молекул RVL, т.е. об уменьшении количества двойных $\mathrm{C}=\mathrm{C}$-связей в результате ионной обработки. Можно предположить, что в результате воздействия ионного пучка происходит фрагментация молекул RVL, либо наблюдается явление разрыва ароматического цикла. Аналогичное явление наблюдали при исследованиях молекул фталидов методом спектроскопии диссоциативного захвата электронов при воздействии электронного пучка [34-36]. Заметим, что энергии электронов, применявшиеся в этих работах, не превышали $10 \mathrm{eV}$, что на два порядка меньше значений энергий ионов $\mathrm{Ar}^{+}$, использовавшихся в нашем эксперименте. В отношении формы XPS-максимума $\mathrm{O}_{1 s}$, ионная очистка привела к уширению и к смещению основной вершины со значений энергии связи 533 на $532 \mathrm{eV}$ (рис. 3,a). Энергетическое положение максимума $\mathrm{O}_{1 s}$ на $533 \mathrm{eV}$ соответствует атомам кислорода, связанным одиночной связью с ароматическим атомом углерода [30-32], а энергетическое положение на $532 \mathrm{eV}$ соответствует атомам кислорода, связанным с алифатическим атомом углерода. Таким образом, изменение формы XPS-максимума $\mathrm{O}_{1 s}$ также может свидетельствовать в пользу уменьшения степени ароматичности молекул RVL в результате проведенной ионной очистки поверхности $\mathrm{Si} / \mathrm{SiO}_{2} / \mathrm{RVL}$.

Результаты диагностики морфологии поверхности исследованных пленок RVL-методом AFM представлены на рис. 4. Пленки RVL создают зернистое и достаточно пористое покрытие поверхности $\left(\mathrm{SiO}_{2}\right) \mathrm{n}-\mathrm{Si}$ подложки, что удобно наблюдать на участках поверхности, размером порядка $10 \mu \mathrm{m} \times 10 \mu \mathrm{m}$ (рис. 4, $a$ ). Характерный размер зерен составлял 200-300 nm в плоскости поверхности образца, а характерный перепад высот достигал $30 \mathrm{~nm}$. Минимумы кривой профиля, т.е. межзеренные области на AFM-изображении соответствуют участкам $\left(\mathrm{SiO}_{2}\right)$ n-Si-поверхности, не покрытым RVL-пленкой. Это было проверено при уменьшении размера области AFM-сканирования. Обнаружение пор в пленке RVL методом AFM вполне соответствует результатам XPS-исследований в настоящей работе, которые показали, что приблизительно 15\% поверхности $\left(\mathrm{SiO}_{2}\right) \mathrm{n}-\mathrm{Si}$-подложки не было покрыто слоем RVL. Для сравнения были проведены исследования морфологии покрытия RVL на поверхности поликристаллического $\mathrm{Au}$ (рис. 4,b). В этом случае пленки RVL также сформировали зернистое и достаточно пористое покрытие. Характерный размер зерен составлял 150-200 nm в 


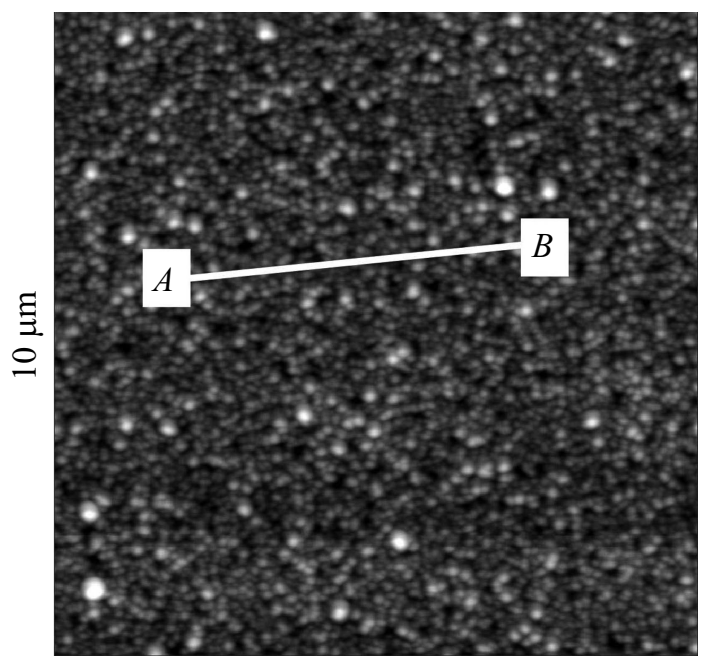

$10 \mu \mathrm{m}$

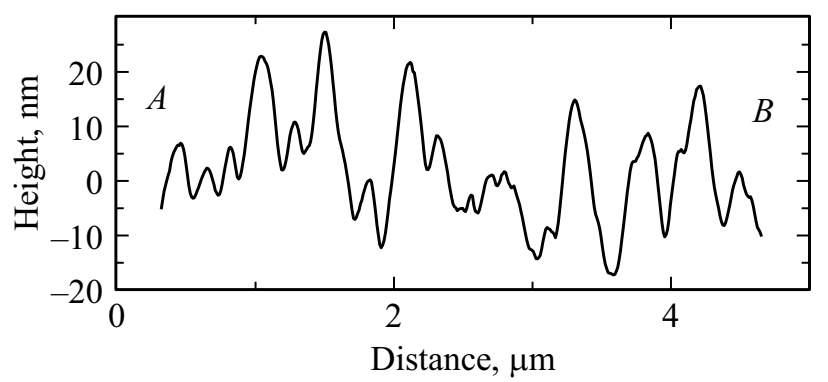

$a$

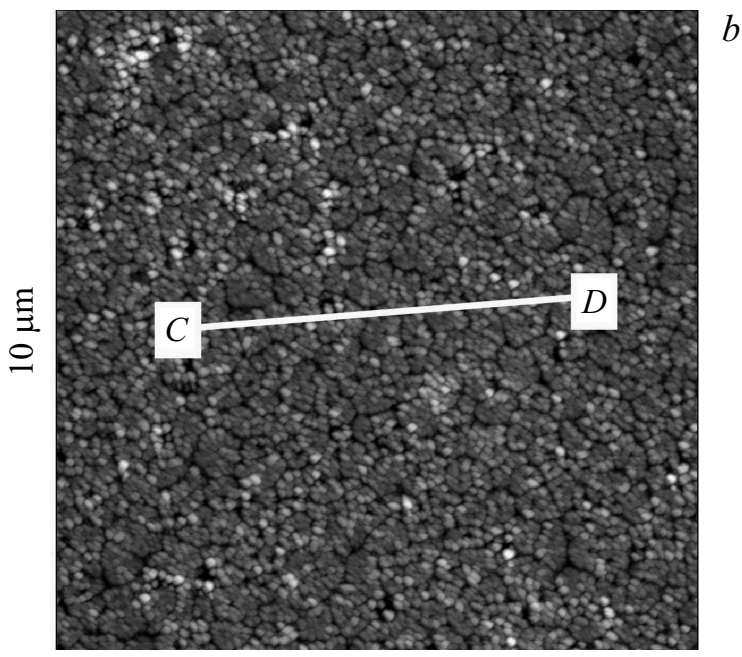

$10 \mu \mathrm{m}$

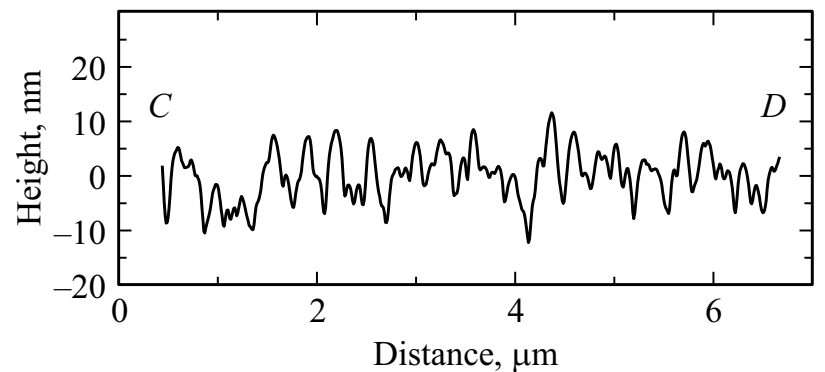

Рис. 4. $a-10 \mu \mathrm{m} \times 10 \mu \mathrm{m} \mathrm{AFM-изображение} \mathrm{участка} \mathrm{исследованной} \mathrm{поверхности} \mathrm{пленки} \mathrm{RVL} \mathrm{на}\left(\mathrm{SiO}_{2}\right) n$-Si подложке. Градации серого цвета от черного до белого соответствуют перепаду высот от 0 до $50 \mathrm{~nm}$. Профиль участка поверхности на отрезке $A-B$ показан снизу. $b-10 \mu \mathrm{m} \times 10 \mu \mathrm{m}$ AFM-изображение участка исследованной поверхности пленки RVL на подложке поликристаллического Аu. Градации серого цвета (см. рис. $4, a$ ). Профиль участка поверхности на отрезке $C-D$ показан снизу.

плоскости поверхности образца, а характерный перепад высот достигал $20 \mathrm{~nm}$, что несколько меньше, чем в случаe RVL-покрытия $\left(\mathrm{SiO}_{2}\right) \mathrm{n}-\mathrm{Si}$-подложки. Тем не менее, межзеренные области на AFM-изображении соответствовали участкам Au подложки без RVL-покрытия. Следует полагать, что при достаточно малой скорости осаждения органического покрытия около $1 \mathrm{~nm} / \mathrm{min}$ в случае слабо взаимодействующих подложек и при фиксированной температуре подложки именно вид органической молекулы, способность молекул образовывать микрокристаллы определяет шероховатость и пористость покрытия [37,38]. Для сравнения с исследованным в работе RVL-покрытием отметим, что пленки других исследованных нами ранее сопряженных органических молекул, имеющие в своем составе несколько фенильных групп, образуют сплошное покрытие поверхности окисленного кремния [19,39].

\section{4. Заключение}

В результате XPS-исследований пленок RVL термически осажденных на поверхность $\left(\mathrm{SiO}_{2}\right) \mathrm{n}-\mathrm{Si}$ показано, что, по крайней мере, $15 \%$ поверхности $\left(\mathrm{SiO}_{2}\right) \mathrm{n}-\mathrm{Si}$-подложки не покрыто слоем RVL. Обработка исследованной по- верхности ионами $\mathrm{Ar}^{+}$с энергией $3 \mathrm{keV}$ при значениях электрического тока через образец порядка $1 \mu \mathrm{A}$ в течение 30 s привела к увеличению площади пор до 30-40\% от общей площади исследованной поверхности. Отншение концентраций атомов C к O в пленке RVL как до ионной обработки поверхности, так и после нее хорошо соответствует химической формуле RVL-молекул. При исследовании морфологии поверхности исследованных пленок RVL методом AFM показано, пленки RVL создают пористое покрытие поверхности $\left(\mathrm{SiO}_{2}\right) \mathrm{n}-\mathrm{Si}$ и поверхности поликристаллического Au. Шероховатость поверхности пленок RVL составила 20-30 nm.

\section{Список литературы}

[1] J.S. Wright, E.R. Johnson, G.A. DiLabio. J. Am. Chem. Soc. 123, 6, 1173 (2001).

[2] М.С. Кочетова, Е.Н. Семенистая, О.Г. Ларионов, А.А. Ревина. Успехи химии 76, 1, 88 (2007).

[3] J.E. Biaglow. Rad. Res. 86, 2, 212 (1981).

[4] S.A. Pshenichnyuk, A.S. Komolov. J. Phys. Chem. Lett. 5, 16, 2916 (2014). 
[5] S.A. Pshenichnyuk, Y.N. Elkin, N.I. Kulesh, E.F. Lazneva, A.S. Komolov. Phys. Chem. Chem. Phys. 17, 26, 16805 (2015).

[6] S.A. Pshenichnyuk, A.S. Komolov. J. Phys. Chem. Lett. 6, 7, 1104 (2015).

[7] S. Ptasinska, S. Denifl, P. Scheier, E. Illenberger, T.D. Mark. Ang. Chem. Int. Ed. 44, 42, 6941 (2005).

[8] D.G. Barrett, T.S. Sileika, P.B. Messersmith. Chem. Commun. 50, 55, 7265 (2014).

[9] S. Gurunathan, J.W. Han, E.S. Kim, J.H. Park, J.-H. Kim. Int. J. Nanomedicine 10, 2951 (2015).

[10] M. Sheikhi, S. Shahab, M.M. Khaleghian, F.H. Hajikolaee, I. Balakhanava, R. Alnajjar. J. Mol. Structur. 1160, 479 (2018).

[11] R.K. Gangwar, V.A. Dhumale, D. Kumari, U.T. Nakate, S.W. Gosavi, R.B. Sharma, S.N. Kale, S. Datar. Mater. Sci. Eng. C 32, 8, 2659 (2012).

[12] M.A. Khan, W.T. Wallace, S.Z. Islam, S. Nagpure, J. Strzalka, J.M. Littleton, S.E. Rankin, B.L. Knutson. ACS Appl. Mater. Interfaces 9, 37, 32114 (2017).

[13] А.Я. Вайнер, К.М. Дюмаев, А.М. Коваленко, Я.Л. Бабушкин, С.А. Кричевская, Ш.И. Тарицкая. ДАН 473, 5, 557 (2017).

[14] J. Leyrer, R. Hunter, M. Rubilar, B. Pavez, E. Morales, S. Torres. Opt. Mater. 60, 411 (2016).

[15] V. Kumar, V.S. Parmar, L. Samuelson, J. Kumar, A.L. Cholli. Am. Chem. Soc., Polymer Preprints, Division of Polymer Chem. 43, 2, 940 (2002).

[16] S.A. Pshenichnyuk, A.S. Komolov. J. Phys. Chem. A 116, 1, 761 (2012).

[17] А.С. Комолов, Э.Ф. Лазнева, Н.Б. Герасимова, Ю.А. Панина, А.В. Барамыгин, С.А. Пшеничнюк. ФТТ 60, 799 (2018).

[18] С.А. Пшеничнюк, А.В. Кухто, И.Н. Кухто, А.С. Комолов. ЖТФ 81, 6, 8 (2011).

[19] A.S. Komolov, E.F. Lazneva, S.N. Akhremtchik, N.S. Chepilko, A.A. Gavrikov. J. Phys. Chem. C 117, 24, 12633 (2013).

[20] А.С. Комолов, Э.Ф. Лазнева, Н.Б. Герасимова, Ю.А. Панина, А.В. Барамыгин, Г.Д. Зашихин, С.А. Пшеничнюк. ФТТ 58, 367 (2016).

[21] П.С. Крылов, А.С. Берестенников, А.Н. Алешин, А.С. Комолов, И.П. Щербаков, В.Н. Петров, И.Н. Трапезникова. ФTT 57, 1639 (2015).

[22] L. Grzadziel, M. Krzywiecki, G. Genchev, A. Erbe. Synth. Met. 223, 199 (2017).

[23] A.S. Komolov, P.J. Moeller. Appl. Surf. Sci. 244, 573 (2005).

[24] A.S. Sizov, D.S. Anisimov, E.V. Agina, O.V. Borshchev, A.V. Bakirov, M.A. Shcherbina, S. Grigorian, V.V. Bruevich, S.N. Chvalun, D.Yu. Paraschuk, S.A. Ponomarenko. Langmuir 30, 50, 15327 (2014).

[25] A.S. Komolov, P.J. Moeller. Appl. Surf. Sci. 212-213, 493 (2003).

[26] Ю.М. Спивак, А.О. Белорус, А.А. Паневин, С.Г. Журавский, В.А. Мошников, К. Беспалова, П.А. Сомов, Ю.М. Жуков, А.С. Комолов, Л.В. Чистякова, Н.Ю. Григорьева. ЖТФ 88, 12, 1394 (2018).

[27] A.S. Lenshin, V.M. Kashkarov, Yu. M. Spivak, V.A. Moshnikov. Mater. Chem. Phys. 135, 293 (2012).

[28] B. Handke, L. Klita, W. Niemiec. Surf. Sci. 666, 70 (2017).

[29] A.S. Komolov, K. Schaumburg, P.J. Moeller, V.V. Monakhov. Appl. Surf. Sci. 142, 591 (1999).
[30] J.F. Moulder, W.F. Stickle, P.E. Sobol, K. Bomben. Handbook of X-ray Photoelectron Spectroscope / Ed. J. Chastain 2nd ed. Eden Prairie: Perkin-Elmer Corporation (Physical Electronics), (1992).

[31] A. Ganguly, S. Sharma, P. Papakonstantinou, J. Hamilton. J. Phys. Chem. C 115, 17009 (2011).

[32] Y.C.G. Kwan, G.M. Ng, C.H.A. Huan. Thin Solid Films 590, 40 (2015).

[33] A.S. Komolov, Y.M. Zhukov, E.F. Lazneva, A.N. Aleshin, S.A. Pshenichnuk, N.B. Gerasimova, Yu.A. Panina, G.D. Zashikhin, A.V. Baramygin. Mater. Des. 113, 319 (2017).

[34] Н.Л. Асфандиаров, С.А. Пшеничнюк, Р.Г. Рахмеев, А.Н. Лачинов, В.А. Крайкин. ЖТФ 88, 1085 (2018).

[35] N.L. Asfandiarov, S.A. Pshenichnyuk, A.S. Vorob'ev, E.P. Nafikova, A.N. Lachinov, V.A. Kraikin, A. Modelli. J. Chem. Phys. 142, 174308 (2015).

[36] S. Ptasińska, D. Gschliesser, P. Bartl, I. Janik, P. Scheier, S. Denifl. J. Chem. Phys. 135, 214309 (2011).

[37] E. Jungyoon, S. Kim, E. Lim, K. Lee, D. Cha, B. Friedman. Appl. Surf. Sci. 205, 274 (2003).

[38] L.G. Kudryashova, M.S. Kazantsev, V.A. Postnikov, V.V. Bruevich, Y.N. Luponosov, N.M. Surin, O.V. Borshchev, S.A. Ponomarenko, M.S. Pshenichnikov, D.Y. Paraschuk. ACS Appl. Mater. Interfaces 8, 10088 (2016).

[39] А.С. Комолов, Э.Ф. Лазнева, Н.Б. Герасимова, Ю.А. Панина, Г.Д. Зашихин, С.А. Пшеничнюк, О.В. Борщев, С.А. Пономаренко, В. Handke. ФТТ 60, 1011 (2018).

Редактор К.В. Емцев 